\title{
The Impact of Innovation Efficiency Factors on the Level of Regional Economic Development
}

\author{
Yue Fang \\ School of Finance, Anhui University of Finance and Economics, Bengbu, China \\ Email: xmgzdlpfy@163.com
}

How to cite this paper: Fang, Y. (2020). The Impact of Innovation Efficiency Factors on the Level of Regional Economic Development. Open Journal of Social Sciences, 8, 343-352.

https://doi.org/10.4236/jss.2020.83031

Received: February 5, 2020

Accepted: March 22, 2020

Published: March 25, 2020

Copyright (C) 2020 by author(s) and Scientific Research Publishing Inc. This work is licensed under the Creative Commons Attribution International License (CC BY 4.0).

http://creativecommons.org/licenses/by/4.0/

\begin{abstract}
In recent years, China's economy has entered a new normal. In the context of the upgrading of the factor endowment structure, it is necessary to reshape regional comparative advantages. This article discusses the impact of economic development on the factors of innovation efficiency in the process of regional economic growth. The empirical verification results of operating Eviews 9.0 software show that: the human capital effect and the asset investment effect have significant effects through the coupling with the innovation factors, respectively. In summary, in the new period, regional development momentum is transformed into policy system design. R \& D should be encouraged according to the characteristics of regional development stages, and policy assistance should be provided at the same time to maximize the commercialization of innovative design of $\mathrm{R} \& \mathrm{D}$ and bring substantial help to regional economic growth.
\end{abstract}

\section{Keywords}

Innovation-Driven, Innovation Efficiency, Commercial assets, R \& D Human Resources, Regional Economic Development, Interaction

\section{Introduction}

In the past 40 years of reform and opening up, China has undergone tremendous changes that have attracted worldwide attention, but at the same time, problems that accompany development cannot be ignored. The national economy has two different manifestations, which are mainly derived from regional and spatial characteristics. From this, each region can be divided into developed regions and less developed regions. This issue makes national leaders and scholars in various fields pay more attention to the current economic development. In May 2014, General Secretary Xi Jinping pointed out that China's economy has shown a new normal, and has turned from high-speed to medium-high-speed growth. 
At the 18th CPC National Congress, General Secretary Xi proposed an innovation-driven development strategy. Under the new normal, the existing imbalances have intensified, and there has been a polarization of economic growth in developed regions that exceed the national average and that in less developed regions that are lower than the national level.

From the perspective of production costs, labor factor costs have increased significantly in recent years, mainly due to changes in the structure of labor market supply and demand. Due to this change, the development of the regional economy is also affected to a certain extent, and the differentiation of regional economic development will also be implicated.

On the whole, the labor force gradually dominates, leading to the delay or even stagnation of industrial transformation, which will undoubtedly exert pressure on the structural balance of the supply side and the demand side, resulting in a bad situation of imbalance (Gao \& Ma, 2019). At present, the difficult factors that cause the domestic market still exist, manifested in terms of consumer demand. The process of increasing consumer demand due to rising incomes cannot be fully transformed into the process of market expansion of domestic products and services, and it cannot generate traction for China's national economy.

From a regional perspective, changes in factor costs have an impact on the regional economy through the formation of a conduction mechanism in the following aspects: first, the increase in factor costs on the pressure and diffusion of enterprises; second, the rise in relative costs against the background of price gradients can help Specific areas gather advanced factors and economic momentum.

On the basis of the above issues, further reflection. In the context of the new development stage and the structural transformation of factor endowments, exploring the mechanism of the role of innovation factors in China's regional economy is undoubtedly an important subject for a deep understanding of the dynamics of regional economic development.

In the process of China's economy moving towards the mid-to-high end, innovation has surpassed other factors and has become the main factor determining the development and improvement of the economic aggregate (Zhang, 2019).

In terms of research on innovation and economic development, the existing literature mainly focuses on empirical research on the impact of innovation input and innovation capacity on economic growth. Only few mathematicians are concerned about innovation efficiency. Based on previous studies, it has been found that the efficiency of scientific and technological innovation has a bearing on regional economies. The conclusion is that the overall level of promotion is not high, and there are obvious regional differences.

Based on the region's own history, natural conditions and other basic factors, there is a large gap in regional economic development. In the context of entering the new normal of economic development, the country vigorously promotes in- 
novative development. Taking these into account, the gap between regions is mainly due to the difference in regional innovation efficiency. Increasing the efficiency of innovation will help optimize the allocation of production factors, promote the rational and efficient flow of resources, and increase total factor productivity so that economic output is effectively increased. China has a vast territory and a large land area. Due to cultural and folklore, ecological geography, and other factors, regional differences have become an important symbol of our country, and become the core factors affecting regional competitiveness and economic development.

This article divides the innovation process into two parts: R \& D and commercialization. Universities, research institutions and enterprises are the main bodies of research and development. They research the market to find new ideas that can stimulate market demand, and then research and develop new technologies. In the process, papers, patents, and product prototypes will be produced. These new ideas that have become possible to promote economic development are the prototypes of finished products. They have great uncertainties and may have good industry prospects, bringing inestimable economic growth to the region. However, due to the region's own reasons or the problems of investors, it may not be able to give full play to its original value, or it will be impossible to develop it into a mature product.

The enterprise is the main body of commercialization, improving raw materials and labor resources for new designs and technologies, transforming new designs and technologies obtained through research and development into new products, and putting them on the market. Putting new technologies and technologies into production is the first step to gain economic benefits. In the entire commercialization process, after the first step, it is necessary to promote the sales operation model and publicity methods, so that innovation can truly achieve the effect of regional development. In the entire commercialization process, the enterprise undoubtedly plays a crucial role, but similar to the research and development process, factors such as the region's own conditions and government systems will also affect commercialization.

In order to further study the impact of innovation factors on regional economic growth, this article introduces the concept of innovation efficiency, and divides innovation efficiency into two types: research and development efficiency and commercialization efficiency.

For the measurement of R \& D efficiency, it is necessary to count the number of invention patent applications in each province; for the measurement of commercialization efficiency, it is necessary to calculate the sales revenue of new products in each province.

\section{Example Analysis of the Impact of Regional Innovation Efficiency on Regional Economic Development}

\subsection{Econometric Model and Variable Description}

This article uses 31 provinces including autonomous regions and municipalities 
from 2009 to 2016 to analyze the role of innovation factors, innovative labor, and innovative capital on regional economic development. Therefore, regional development is the explanatory variable and innovation efficiency is the key explanatory variable. Based on the above analysis, the measurement model set in this article is as follows:

$$
y=b_{0}+\beta X_{i}+\mu_{i}
$$

In the formula, $y_{i}$ represents the regional economic development indicator for the GDP of each province in 2016.

$X_{i}$ is an independent variable matrix containing different variables such as innovation efficiency, $\mu_{i}$ is the random error term.

The explanatory variable: the level of regional economic development. In this article, it is reflected by the GDP index of each province $\left(y_{i}\right)$.

Where $y_{i}$ is the GDP of provinces and cities $i$ in 2016.

Core explanatory variables:

Regional innovation efficiency, Commercial efficiency $x_{1 i}$, and R \& D efficiency $X_{2 i}$ are the core variables that this article focuses on.

The measurement of $\mathrm{R} \& \mathrm{D}$ efficiency requires the number of invention patent applications in each province as an indicator of output; the measurement of commercialization efficiency requires the sales of new products in each province as an indicator of output.

From the perspective of output, it is measured by the number of patent applications; from the perspective of input, it is measured by the sales revenue of new products in each province (Cui \& Chen, 2019).

Theoretically, the higher the investment in innovation, the more it stimulates innovation activities and is conducive to economic development, but it also means the scarcity of scarce economic resources, especially for less developed regions, which may not be good for economic development in the short term This requires further verification.

In view of this, the interaction term is introduced to grasp the heterogeneity of the role of innovation efficiency.

In order to capture possible non-linear effects, consider setting innovation efficiency indicators separately. Innovative human resources (unit: 10,000 people) include commercial human resources and $\mathrm{R} \& \mathrm{D}$ human resources $\left(x_{1 i} *\right.$ labor $_{i}$ $\& x_{2 i} *$ labor $_{i}$ ), and innovation assets (unit: 100 million yuan) include business And R \& D assets $\left(x_{1 i} * c a p_{i} \& x_{2 i} * \operatorname{cap}_{i}\right)$.

May define Commercial Human Resources as $x_{3 i}$, R \& D Human Resources are defined as $x_{4 i}$, Commercial assets are defined as $x_{5 i}$, Define $\mathrm{R} \& \mathrm{D}$ assets as $x_{6 i}$.

\subsection{Data Sources}

The data of the major basic variables such as GDP, labor force population, fixed assets, number of patent applications, and sales revenue of new products from various provinces are derived from relevant data such as the China Statistical Yearbook. 


\subsection{Model Estimation, Testing and Adjustment}

\subsubsection{Least Square Estimation}

Operate Eviews 9.0 software to perform least square estimation (OLS) on the model. Firstly, a separate regression analysis was performed for each explanatory variable. The related regression results are summarized in Table 1 below.

Regressione as can be seen from the above table, $x_{1 i}, x_{2 i}, x_{3 i}, x_{5 i}, x_{4 i}, x_{6 i}$ can affect the regional economy through inspection. However, the regression of the model is not high. The commercialization efficiency alone does not have a significant impact on regional economic development, and the R \& D efficiency is not high in the regional economic development. The $\mathrm{R} \& \mathrm{D}$ efficiency is lower than the commercialization efficiency.

The $x_{3 i}$ Commercial Human Resources have a much better fitting degree than the $x_{1 i}$ model. It can be seen that the commercialization efficiency has a more significant impact on the regional economy by interacting with human resources, and the interaction effect makes the model's goodness of fit improved.

Then perform OLS regression on $x_{4 i}$ ( $\mathrm{R} \& \mathrm{D}$ Human Resources). This model has a better fit than the $x_{3 i}$ model, indicating that the impact of research and development efficiency on regional economic development through human resources is more obvious.

In the same way, the effect of $x_{5 i}$ commercialization efficiency on the regional economy through assets is more significant, and the effect on the explanatory variables under the influence of interaction is more significant.

The analysis of $x_{6 i}$ regression results shows that, similarly to $x_{5 i}, \mathrm{R} \& \mathrm{D}$ efficiency can greatly improve the model through interaction with assets. From the above analysis, under the research background of this article, the interaction terms of innovation efficiency factors and human resources and assets can obviously obtain a more optimized model (Zhou \& Zhang, 2019).

\subsubsection{Model Multicollinearity Test}

For the accuracy of the model, we did a multicollinearity test of the model (see Table 2).

Table 1. Regression test of single innovation efficiency factor on regional economy.

\begin{tabular}{|c|c|c|c|c|c|c|}
\hline & $\mathrm{x} 1$ & $\mathrm{x} 2$ & $\mathrm{x} 3$ & $\mathrm{x} 4$ & $\mathrm{x} 5$ & $\mathrm{x} 6$ \\
\hline variabie & $\begin{array}{l}\text { Commercial } \\
\text { efficiency }\end{array}$ & R \& D efficiency & $\begin{array}{c}\text { Commercial Human } \\
\text { Resources }\end{array}$ & $\begin{array}{l}\text { R \& D Human } \\
\text { Resources }\end{array}$ & Commercial assets & $\mathrm{R} \& \mathrm{D}$ assets \\
\hline Parameter estimates & $61172.45^{* * *}$ & $57835.33^{* * *}$ & $6.4498^{* * *}$ & $6.1524^{\star * *}$ & $1.3363^{* * *}$ & $1.3071^{* * *}$ \\
\hline $\mathrm{t}$ value & 4.8270 & 4.4480 & 10.1744 & 9.7551 & 10.0427 & 10.2792 \\
\hline$P$-value (bilateral probability) & 0.0000 & 0.0001 & 0.0000 & 0.0000 & 0.0000 & 0.0000 \\
\hline $\mathrm{R}^{\wedge} 2$ & 0.4455 & 0.4056 & 0.7812 & 0.7664 & 0.7767 & 0.7846 \\
\hline
\end{tabular}

Note: The $t$ value is in parentheses, ${ }^{* * *}$ : indicates a significance level of $1 \%,{ }^{* *}$ : indicates a significance level of $5 \%$, and ${ }^{*}$ indicates a significance level of $10 \%$. 
Table 2. Correlation coefficient.

\begin{tabular}{|c|c|c|c|c|c|c|c|}
\hline Correlation & $\mathrm{Y}$ & $\mathrm{X} 1$ & $\mathrm{X} 2$ & $\mathrm{X} 3$ & $\mathrm{X} 4$ & $\mathrm{X} 5$ & $\mathrm{X} 6$ \\
\hline Y & 1.000000 & & & & & & \\
\hline $\mathrm{X} 1$ & 0.667468 & 1.000000 & & & & & \\
\hline $\mathrm{X} 2$ & 0.636828 & 0.675908 & 1.000000 & & & & \\
\hline $\mathrm{X} 3$ & 0.883834 & 0.752725 & 0.595437 & 1.000000 & & & \\
\hline $\mathrm{X} 4$ & 0.875463 & 0.671256 & 0.659879 & 0.972025 & 1.000000 & & \\
\hline $\mathrm{X} 5$ & 0.881292 & 0.771081 & 0.575195 & 0.926349 & 0.580899 & 1.000000 & \\
\hline X6 & 0.885802 & 0.709564 & 0.637496 & 0.912154 & 0.911491 & 0.980489 & 1.000000 \\
\hline
\end{tabular}

\subsubsection{Determination of Model Explanatory Variables}

In this study, the model explanatory variables are first determined. For details, see Table 3.

According to the regression test, when there are more than three explanatory variables in the model, two explanatory variables fail to pass the test. In the combination of the two explanatory variables, we consider the significance level and the value of the goodness of fit $R^{2} \cdot X_{4 i}$ (R \& D Human Resources) and $x_{5 i}$ (Commercial assets) are finally determined as the explanatory variables of the model for least squares estimation.

\subsubsection{Economic Significance Test}

From the above analysis, after considering various aspects, the optimal choice of X4 (R \& D Human Resources) and X5 (Commercial assets).

The final model was determined as:

$$
\begin{aligned}
y_{i} & =1438.243+3.109923 X_{4 i}+0.745229 X_{5 i}+\mu_{i} \\
R^{2} & =0.8205 \text { Adjusted } R^{2}=0.8077, F=64.0139
\end{aligned}
$$

It shows that the state of regional economic development is ultimately greatly affected by the number of innovative $\mathrm{R} \& \mathrm{D}$ in the region and the funds invested by local governments and enterprises to put $\mathrm{R} \& \mathrm{D}$ design and technology into production and eventually become new technology products entering the market.

For every 10,000 effective R \& D labors added, the province's GDP will increase by $31,099.2$ million yuan.

For every 100 million yuan of commercialized assets, the province's GDP will increase by 744.5229 million yuan.

\subsubsection{Statistical Test}

The least squares estimation results show that $R^{2}=0.820545$, which indicates that the interpretation ability of the regression line of the sample is $82.05 \%$, and the goodness of fit of the simulation is high.

At the significance level of $1 \%, F=64.0139>3.34$, the $F$ test was passed.

Judging from the $\mathrm{t}$-test value of the slope term, $x_{4 i}$ ( $\mathrm{R} \& \mathrm{D}$ human resources) and $x_{5 i}$ (Commercial assets) were significant at the $5 \%$ and $1 \%$ levels, respectively. Passing the test has a significant impact on the explanatory variables. 
Table 3. Innovation efficiency and regional economic development.

\begin{tabular}{|c|c|c|c|c|c|c|c|}
\hline variable & (1) & (2) & (3) & (4) & (5) & (6) & (7) \\
\hline $\mathrm{x} 1$ & $\begin{array}{c}39,995.54^{* *} \\
(2.4287)\end{array}$ & & & & & & \\
\hline $\mathrm{x} 2$ & $\begin{array}{c}31,047.07^{\star} \\
(1.9026)\end{array}$ & $\begin{array}{c}15,556.36 \\
(1.6287)\end{array}$ & & & & & \\
\hline $\mathrm{x} 3$ & & $\begin{array}{c}5.7055^{* * *} \\
(7.4340)\end{array}$ & $\begin{array}{l}3.4693^{* *} \\
(2.1667)\end{array}$ & & & & $\begin{array}{c}2.7523 \\
(1.0424)\end{array}$ \\
\hline $\mathrm{x} 4$ & & & & $\begin{array}{l}3.1099^{* *} \\
(2.6162)\end{array}$ & $\begin{array}{l}2.8271^{*} \\
(2.0196)\end{array}$ & $\begin{array}{l}3.0803^{* *} \\
(2.1836)\end{array}$ & $\begin{array}{c}0.6244 \\
(0.2464)\end{array}$ \\
\hline $\mathrm{x} 5$ & & & $\begin{array}{l}0.6685^{*} \\
(2.0093)\end{array}$ & $\begin{array}{c}0.7452^{* * *} \\
(2.9056)\end{array}$ & & $\begin{array}{c}0.7215 \\
(1.1328)\end{array}$ & \\
\hline $\mathrm{x} 6$ & & & & & $\begin{array}{c}0.7660^{* *} \\
(2.606)\end{array}$ & $\begin{array}{c}0.0291 \\
(0.0409)\end{array}$ & $\begin{array}{l}0.6800^{* *} \\
(2.2302)\end{array}$ \\
\hline
\end{tabular}

Note: The $t$ value is in parentheses, ${ }^{* * *}$ : indicates a significance level of $1 \%,{ }^{* *}$ : indicates a significance level of $5 \%$, and ${ }^{*}$ : indicates a significance level of $10 \%$.

\subsubsection{Econometric Inspection}

After satisfying the statistical test, taking into account the differences in the units of the population in the cross-section data, the white test method was used to perform a heteroscedasticity test on the model. According to the White test, at the $5 \%$ level, there is no heteroscedasticity.

\section{Statistical Description of Variables}

Based on the data of various provinces in 2016, the analysis shows that the maximum GDP in 2016 was 79.251 billion yuan. In Guangdong Province, it is easier to know. At the same time, Guangdong's R \& D human resources are also ranked first, and the maximum value of $\mathrm{R} \& \mathrm{D}$ human resources is $10,329.90171$ billion. Ranked fourth in commercialized assets, at 31,635,979,746 million yuan.

In 2016, the maximum value of commercialized assets was 4766.258 trillion yuan. In Shandong Province, from observation data, Shandong province's GDP ranked third with 67.00819 billion yuan and R \& D human resources ranked second with 944.041 trillion yuan.

In 2016, the minimum value of GDP was 115.007 billion yuan in Tibet. At the same time, the minimum value of $\mathrm{R} \& \mathrm{D}$ human resources and commercial assets were in Tibet, which was 6.223533 billion yuan and 6.352279 billion yuan, respectively.

It is not difficult to find that the model designed in this paper is highly in line with actual values and has great economic significance.

\section{Conclusion and Recommendations}

\subsection{Conclusion}

This article examines the effects of regional innovation efficiency, research and 
development efficiency, and commercialization efficiency on economic growth.

First, the efficiency of innovation can promote the development of regional economy and have a positive impact, but it is not difficult to find that its impact is slightly inferior compared with the capital and labor factors. Therefore, while acknowledging the status of innovation, analysis shows that innovation has not yet become a decisive driving force for China's regional economic development.

Second, Innovation efficiency factors (including commercialization efficiency and R \& D efficiency) will have a greater impact on the economy through interaction with human resources and assets. According to a series of econometric tests and statistical descriptions, it can be obvious it can be seen that commercialized assets $\left(x_{1 i} * c a p_{i}\right)$ and $\mathrm{R} \& \mathrm{D}$ human resources $\left(x_{2 i} *\right.$ labor $\left._{i}\right)$ have a significant impact on regional economic development.

Third, China's economic growth has spillover effects between provinces, but it is inferior to capital and labor, and its regional growth poles have weak radiation-driven capabilities, which need to be taken seriously and gradually strengthened.

The efficiency of regional commercialization in China is significantly lower than the efficiency of research and development, and the ability to promote the transfer and transformation of scientific and technological achievements in most regions is still insufficient.

Whether in terms of commercialization efficiency or R \& D efficiency, the eastern region is in a relatively leading position compared with other regions, the central region is closely followed, and the western region has the lowest innovation efficiency. In the statistical description, we found that Tibet's commercialization efficiency, research and development human resources and GDP were the lowest in 2016.

\subsection{Recommendations}

Based on the conclusions of the above analysis, the following policy recommendations are proposed.

\subsubsection{Establish and Improve the Coordination Mechanism for the Transformation of relevant Scientific and Technological Achievements}

The transformation of scientific and technological achievements involves multiple steps such as product research, technological development, commercial transformation, and industrialization (Piao, Miao, \& Zhang, 2019). There are also many related factors such as information, technology, talents, and funds. Both local governments and central governments need to formulate relevant plans in detail. The inter-departmental scientific and technological achievements transformation policy coordinating agency can solve the commercialization of scientific and technological achievements more efficiently.

4.2.2. The Government Increases Support for Commercial Enterprises According to the research results in this paper, under the interactive influence of 
commercialization efficiency and fixed assets, the regional economy can grow and develop. For some regions, due to their own constraints, their enterprises cannot effectively complete the commercialization process (Zhang \& Xi, 2019). The central and local governments should intervene to encourage and support at this time, which can be more directly expressed as funding assistance, coupled with talent Assistance is more effective. Because regional economic growth is also affected by the interaction of research and development efficiency and human resources. I believe that with the help of the government, the regional economy can develop more efficiently.

\subsubsection{Local Governments Strengthen the Cultivation of Innovation}

Take corresponding measures to effectively increase $\mathrm{R} \& \mathrm{D}$ talents in the region. In order to achieve this goal, young children can strengthen their training in innovation, implement innovation courses, and start with dolls; encourage the promotion of innovation competitions in universities, set related awards, and attract more talents to join the path of research and development; in society At the level, through the use of star effects and multimedia effects such as the Internet to carry out innovative publicity, and the government appropriately formulates and issues relevant written regulations, the research and development human resources can be greatly improved, and then combined with commercial transformation, effectively and rapidly driving regional economic development (Xi, 2019).

\subsubsection{Promote Regional Resource Sharing and Collaborative Innovation} The central government encourages joint innovation, creates provincial and municipal cooperation projects, and establishes resource sharing mechanisms. In the context of the Internet era, the established resource market platform has broken regional administrative protection and monopoly, and promoted the multi-directional flow of resources. This article finds that Tibet's regional economic level in 2016 is extremely low compared with other provinces (Gao, 2019). The Tibetan government should pay attention to it, not only starting from the above commercialized assets and R \& D human resources, but also sharing resources and experience. The development of other provinces drives the development of this province. For example, R \& D ideas that are relatively advanced but not capable of commercial transformation can be directly shared with the more capable provinces to achieve common development. Or it can directly use the advantages of its natural resources to develop its own business model to attract foreign investment to achieve the purpose of regional development.

Geographical conditions, historical factors, resource factors and other development conditions in each region of China are different. Provinces need to consider their own advantages, seek strengths and avoid weaknesses, and find ways of technological innovation and industrial rise, while avoiding high levels of industry overlap with other regions, causing waste of resources the bad results. And each region needs to work hard to learn and exchange with other regions, 
carry out cooperation projects, uphold an active and open mind, communicate and collaborate with other provinces, and learn from the advantages of other provinces' development paths, so that the province can obtain more high-quality economic growth (Liu \& Gao, 2019).

\section{Conflicts of Interest}

The author declares no conflicts of interest regarding the publication of this paper.

\section{References}

Cui, Z. X., \& Chen, Y. (2019). Research on the Influencing Factors of Regional Technological Innovation Synergy-Empirical Analysis Based on Regional Panel Data of Beijing-Tianjin-Hebei and Yangtze River Delta. Economics and Management, 33, 1-8.

Gao, L. N., \& Ma, Y. (2019). Innovation, Upgrading of Labor Factors and Regional Economic Growth. Journal of Southwest University for Nationalities (Humanities and Social Sciences), 40, 95-101.

Gao, Y. (2019). Structural Changes in Population, Regional Innovation and Transformation and Upgrading of Economic Structure. Commercial Economics Research, No. 9, 189-192.

Liu, J. H., \& Gao, M. (2019). Analysis of Influencing Factors of China's Grain Output Based on Econometrics. Shanxi Agricultural Economics, No. 4, 31.

Piao, Z. F., Miao, B. B., \& Zhang, W. E. (2019). Research on the Evaluation of Regional Economic Innovation and Development Ability: A Case Study of Zhejiang Province. Journal of Hebei University of Economics and Trade, 40, 87-93.

Xi, G. F. (2019). An Empirical Analysis of the Relationship between Innovation, Human Capital and Regional Economic Growth. Modern Business Industry, 40, 1-3.

Zhang, F. (2019). Empirical Research on Regional Innovation Efficiency and Economic Growth. China Soft Science, No. 2, 155-162.

Zhang, Z. Q., \& Xi, Q. M. (2019). New Progress in the Study of the Theory and Practice of China's Regional Economy in the New Era: A Summary of the First Forum of China's Regional Economists. Economic Research, 54, 199-203.

Zhou, G. F., \& Zhang, C. H. (2019). Spatial Econometric Research on Regional Innovation Capability and Total Factor Productivity. East China Economic Management, 33, 61-68. 